Etnográfica

Revista do Centro em Rede de Investigação em

Antropologia

vol. $23(2) \mid 2019$

Vol. $23(2)$

\title{
No-humanos que hacen la historia, el entorno y el cuerpo en el chaco argentino
}

Non-humans making history, the environment and the body in the Argentinean Chaco

\section{Florencia Tola}

\section{(2) OpenEdition}

Journals

Edición electrónica

URL: https://journals.openedition.org/etnografica/6913

DOI: 10.4000/etnografica.6913

ISSN: 2182-2891

\section{Editor}

Centro em Rede de Investigação em Antropologia

Edición impresa

Fecha de publicación: 1 junio 2019

Paginación: 489-513

ISSN: 0873-6561

\section{Referencia electrónica}

Florencia Tola, «No-humanos que hacen la historia, el entorno y el cuerpo en el Chaco argentino», Etnográfica [En línea], vol. 23 (2) | 2019, Publicado el 25 junio 2019, consultado el 19 enero 2022. URL: http://journals.openedition.org/etnografica/6913 ; DOI: https://doi.org/10.4000/etnografica.6913

Etnográfica is licensed under a Creative Commons Attribution-NonCommercial 4.0 International License. 


\section{No-humanos que hacen la historia, el entorno y el cuerpo en el Chaco argentino}

\section{Florencia Tola}

Exploramos los efectos de ciertas entidades no-humanas (fenómenos atmosféricos, muertos, dueños de animales, pájaros) en la vida cotidiana, en la historia y en el cuerpo de los indígenas tobas (qom) del Chaco argentino. Para eso, analizamos algunos relatos indígenas sobre la conquista estatal de sus territorios en finales del siglo XIX en los que el accionar de estas entidades incidió en el devenir de los antiguos qom y en sus desplazamientos mientras huían de los frentes de conquista y colonización. Mostramos que el entorno, un espacio vivido y cargado de intencionalidad y agencia, presenta características que son la consecuencia del accionar de estas entidades no-humanas. Estas dejan huellas que son leídas por los seres humanos en su permanente transitar por los lugares de su territorio. Por último, exponemos situaciones de la vida cotidiana ocurridas durante nuestra etnografía (desde 1997 hasta el presente) que dan cuenta de los efectos de las intencionalidades "otras" (más allá de las humanas) sobre el cuerpo. A partir de la etnografía llevada a cabo en el Chaco central profundizamos en la relación humano-no-humano y en el modo en que para este grupo indígena la historia, el entorno y el cuerpo no se hallan al margen del ensamblaje humano-no-humano sino que son co-construidos por él.

PALABRAS-CLAVE: Gran Chaco, tobas, cuerpo, historicidad, cosmología.

Non-humans making history, the environment and the body in the Argentinean Chaco - The article explores the effects of certain non-human entities (atmospheric phenomena, dead beings, masters of animals, birds) on everyday life, the history and the body of the Toba (Qom) native people in the Chaco region, Argentina. Native narratives are analyzed, regarding the State's takeover of their territories in the late $19^{\text {th }}$ century and how such entities impacted on the life of the ancient Qom and their displacements while fleeing conquest and colonization fronts. Likewise, the environment, in addition to being a lived space carrying intentionality and agency, presents certain features as a result of the mobilization of non-human entities. These leave traces that are read by humans in their constant transits throughout their territory. Finally, everyday-life situations observed during fieldwork (since 1997) show effects of "other" intentionalities (besides the human ones) on the body. Ethnography carried out in central Chaco is the basis for inquiring the human-non-human relationship and how history, the environment and the body among this native people are not detached from the human-non-human assemblage, but rather co-produced by it.

KEYWORDS: Gran Chaco, Toba people, body, historicity, cosmology.

TOLA, Florencia (tolatoba2015@gmail.com) - Consejo Nacional de Investigaciones Científicas y Técnicas (Conicet), Argentina; EREA-LESC, Francia. 


\section{INTRODUCCIÓN}

Hacia fines de la década de 1990 comencé a hacer trabajo de campo entre los tobas (qom) de la provincia de Formosa, en el Chaco argentino. A los pocos meses de estar en Formosa, me instalé en Namqom, el barrio toba situado a las afueras de la ciudad, a vivir en la pequeña y modesta casa de un reconocido chamán junto con sus seis hijos, los cónyuges de algunos de ellos, su esposa y varios de sus nietos. Si bien por aquellos años el barrio toba no tenía las características que fue adquiriendo con el paso del tiempo (superpoblación, marginalidad, violencia, droga y prostitución), no era necesariamente un lugar calmo donde llevar adelante una primera experiencia etnográfica, ni una comunidad alejada de la ciudad y ubicada en el medio de la selva ("monte"). Por las noches, en Namqom se oían los gritos de los borrachos, se escuchaban peleas entre bandas enemigas y por las mañanas nos enterábamos si habían habido acuchillados, si la policía había golpeado y apresado a algún borracho, si habían violado a alguna joven o si los camioneros que pasaban por la ruta habían atropellado a alguien.

A pesar de las condiciones adversas, lentamente fui entrando en el universo más íntimo de varias de las personas que allí viven. A medida que la confianza lo iba permitiendo, hombres y mujeres me fueron expresando ideas que cualquier naturalista calificaría de irracionales o absurdas. En diversos escenarios discursivos y prácticos, hombres y mujeres referían no solo la existencia de entidades desconocidas para mí y para cualquier no-indígena, sino que también aludían a la posibilidad de entablar con ellas relaciones que serían impensables para alguien cuyos conocimientos del mundo se estructuran sobre uno de los pilares del Occidente moderno: la "gran división" naturaleza/cultura. ${ }^{1}$ Manchas negras en la piel eran entonces explicadas como las huellas de los golpes de pel'ec (el ser no-humano de la noche), ${ }^{2}$ las separaciones de parejas eran

1 La oposición naturaleza/cultura se constituyó, desde el comienzo de la disciplina, como uno de sus dogmas y proveyó las herramientas analíticas para investigaciones antropológicas en diversas sociedades. Las cosmologías indígenas, las nociones de cuerpo y persona, las ontologías, las relaciones con el entorno fueron leídas bajo el lente de esta oposición (ya sea enfatizando en el factor determinista de la naturaleza sobre la cultura, ya sea enfatizando en la forma en que la cultura atribuye sentido a la naturaleza) o de alguno de sus derivados centrales: biológico/social, dado/construido, cuerpo/mente, emoción/cognición, material/espiritual, inmanencia/trascendencia, físico/moral, etc. Hace ya varias décadas, investigaciones antropológicas muestran que esta oposición está lejos de expresarse de este modo en todas las sociedades a lo largo de la historia e incluso algunos autores sugieren que esta dicotomía sería la gran especificidad del Occidente moderno (cf. Wagner 1975; Strathern 1988; Latour 1991; Descola 1996). En las últimas décadas también, en la disciplina se replanteó el uso de categorías europeas-americanas para abordar realidades sociales no europeas. La dicotomía naturaleza/cultura y los rasgos asociados a ella fueron reformulados y dieron paso a repensar el dominio de lo dado y de lo construido para otras realidades etnográficas.

2 Para la transcripción de las palabras y expresiones en toba utilizamos los siguientes símbolos fonéticos: /sh/ (fricativa palatal sorda), /q/ (oclusiva uvular sorda), /x/ (oclusiva uvular sonora), /'/ (oclusiva laríngea sorda), / y / (palatal sonora) (cf. Messineo 2003). 
fruto del polvo de huesos de muerto esparcidos en los hogares, una malformación de nacimiento era la consecuencia de una cercanía extrema con alguna presa durante la gestación y un ronquido nocturno en un bebé era el fruto de la fusión del espíritu del jaguar con el del bebé.

Lo que llamaba mi atención - y que fue delineando a lo largo de mi etnografía mi replanteo, para el Chaco, de la oposición en cuestión - era que las relaciones y acontecimientos que los qom describían no podían ser catalogados ni como fenómenos naturales, ni como sucesos espirituales, ni como acontecimientos externos a un cuerpo pensado como biológico. Lejos de ser un hecho natural sobre el cual la cultura desplegaría un sistema de significados, el cuerpo-persona se mostraba entre mis interlocutores como un espacio socialmente transformado que tenía como motor otros acontecimientos en los cuales diversas entidades intervenían y detonaban sucesivas transformaciones. Diversos ámbitos de mi experiencia etnográfica me fueron conduciendo a la necesidad de pensar y hablar de las experiencias vitales de mis interlocutores de un modo que no estuviera sesgado por la manera en que nuestra ontología ubica ciertos fenómenos en el ámbito de la naturaleza (lo universal, lo rutinario y mecánico, lo no-intencional, etc.) y otros en el de la cultura (lo particular, lo creativo, variable e intencional). Por otro lado, no dejaba de sorprenderme que aquello que mis interlocutores referían no quedaba tampoco en el plano discursivo: las experiencias que me referían no eran ni puras metáforas usadas por ellos para hablar de otras cosas (que yo debía descifrar), ni remitían a entidades que podríamos imaginar como pertenecientes a un pasado mítico. Las relaciones entabladas con eses seres que los tobas me referían eran vividas como relaciones tangibles, audibles y concretas con entidades inmanentes al mundo de los seres humanos. ${ }^{3}$

De hecho, la diversidad de situaciones de la vida cotidiana en la que los tobas entablan vínculos y comunicación con animales, plantas, fenómenos atmosféricos y otros seres no-humanos deja entrever la centralidad de estos lazos para sus vidas. Las causas posibles de una enfermedad, de una malformación, de una expresión de locura o de un desengaño amoroso, remitían generalmente a la intencionalidad y agencia de seres que solemos calificar de criaturas imaginarias, proyecciones o expresiones simbólicas de los hombres; únicos poseedores de cualidades de interioridad. Para los qom, como para otros pueblos amerindios, estas entidades se presentan, según el contexto y las

3 Destacamos, como un antecedente al tipo de reflexión del presente texto, los trabajos de P. Wright (2008: 24), que constituyen un acercamiento existencialista nutrido de una experiencia intercultural. En su obra, el antropólogo indaga sobre la ontología desde la filosofía europea, esencialmente, y desde la filosofía amerindia. Se pregunta por la forma en que "otras formas de vida" afectaron su "estructura existencial” (2008: 42) y refiere al modo en que la experiencia etnográfica con indígenas tobas lo condujeron a "explorar su filosofía de vida, básicamente su visión del ser y el conocimiento" (2008: 43). 
interacciones entabladas, como sujetos sintientes, conscientes y activos interlocutores de un sistema de comunicación. ${ }^{4}$

En este artículo me propongo explorar los efectos de los seres no-humanos en la historia, el entorno y el cuerpo de este pueblo indígena sudamericano. Para eso, me referiré a relatos antiguos sobre la conquista de sus territorios en los que el accionar de estos seres (fenómenos atmosféricos, muertos, dueños de animales, pájaros) incidió en el devenir de los qom y en sus desplazamientos, huyendo de los frentes de conquista y colonización comenzadas a finales del siglo XIX. Luego, mostraré que el entorno - lejos de ser un espacio neutro que provee recursos naturales a los cazadores y además de ser un espacio vivido y cargado de agencia - presenta determinadas características que son leídas como las huellas que en él dejan los seres no-humanos. Por último, expondré algunas situaciones de la vida cotidiana que dan cuenta de los efectos de las intencionalidades y agencias "otras" sobre el cuerpo de los humanos.

No es mi intención introducir los conceptos y las categorías antropológicas que irán surgiendo a lo largo de este trabajo y con las cuales dialogaré, ya que mi propuesta consiste en que los datos etnográficos sean los que orienten el debate y dicten, ellos, los términos de su propio análisis. A pesar de esto, cabe aclarar que, sin lugar a dudas, mi perspectiva se halla inserta en un conjunto de propuestas antropológicas que han nutrido no solo mi lectura de los hechos descritos, sino la posibilidad misma de observarlos y registrarlos. Ahora bien, no intento con este texto otorgarle autoridad epistémica a los autores con los cuales dialogo, sino más bien intentar simetrizar antropologías al reconocer que "los 'Otros' también hacen antropología y que sus teorías son equivalentes a las nuestras" (Cayón 2018: 36). Este texto no pretende ser más que un aporte a la antropología que, más que interpretar el mundo de los "otros", intenta dejarles una vía de escape (Holbraad, Pedersen y Castro 2014); más que definir, "infinir"... (Holbraad and Pedersen 2017).

4 Utilizo los términos "pueblo indígena", "indígena”, "pueblo amerindio", "pueblos originarios" o "aborígenes" indistintamente. El uso indistinto de los términos no conlleva un desconocimiento del origen colonial de algunos de ellos, ni tampoco el hecho de que las variaciones en la utilización de estos términos responden a la historia de las relaciones que los países o sectores colonizadores sostienen y han sostenido con dichos pueblos. Si hace diez años los qom se reconocían como "aborígenes", hoy en día algunos de ellos prefieren ser llamados "indígenas". Otros, en cambio, se autodenominan qom y les es completamente indiferente que se los llame "amerindio" o "pueblo originario" pues ambas denominaciones son hechas por no-indígenas y ellos no consideran que "amerindio" sea más o menos incorrecto que "pueblo originario". Sobre el uso indistinto de "aborigen" y "amerindio", ver también Wright, quien, por momentos, habla de "grupos aborígenes" (2008: 23), por momentos, de "filosofía amerindia” (2008: 34) y, por momentos, de "pensamiento indígena” (2008: 35). 


\section{HISTORICIDAD HUMANA Y NO-HUMANA}

El Gran Chaco constituye el tercer gran territorio biogeográfico y morfoestructural de América Latina después del Amazonas y el Sistema Sabánico Sudamericano, y el segundo en superficie cubierta por bosques después de las selvas pluviales tropicales del Amazonas y del Pacífico colombo-ecuatorianas. Ocupa más de $1.000 .000 \mathrm{~km}^{2}$ y se extiende a lo largo de cuatro países (Argentina, Bolivia, Paraguay y Brasil), siendo el área desplegada en Argentina la más extensa (Morello, Rodríguez y Silva 2009). En esta región viven individuos pertenecientes a 24 pueblos indígenas que hablan lenguas agrupadas en seis familias lingüísticas: guaycurú (toba/qom, pilagá, toba-pilagá, mocoví y caduveo/eyiguayegui ${ }^{5}$ ), mataco-mataguaya (mataco/wichí, chulupi/nivaklé, chorote/manjui y maká), tupi-guaraní (chiriguano/avá, guaraní ñandeva/tapiete, chané, isoseño/guaraní y guaraní occidental), enlhet-enenlhet (enxet/lengua sur, enlhet/lengua norte, angaité, sanapaná, guaná y toba-maskoy/enenlhet), ${ }^{6}$ lule-vilela (vilela/chunupí) y zamuco (chamacoco/ishir ebidoso, chamacoco/ ishir tomaraho y ayoreo)..$^{7}$ Tradicionalmente, los pueblos chaqueños tenían una tradición cazadora-recolectora, se organizaban en lo que la literatura etnográfica denomina "bandas" y "tribus" y existían diversos subgrupos dentro de un mismo grupo étnico (Braunstein 1983). Con la ocupación de los territorios del Chaco argentino por las fuerzas militares a finales de 1800 y tras la colonización, los indígenas fueron violentamente forzados a instalarse de forma sedentaria en comunidades agrícolas y a trabajar en obrajes madereros e ingenios azucareros. ${ }^{8}$ En 1911 se llevó a cabo la campaña militar de Rostagno, que restableció definitivamente la línea de fortines sobre el Bermejo y permitió que en 1915 se concluyera la misión de las fuerzas militares de ocupación (Altamirano, Sbardella y Dellamea de Prieto 1987).

En la segunda y tercera década del siglo XX emergieron movimientos indígenas, algunos de los cuales tuvieron características mesiánicas (Cordeu y Siffredi 1971) que contrarrestaron la ocupación acelerada de las tierras y las desfavorables condiciones de trabajo a las que eran sometidos los indígenas. A principios del siglo XX se crearon misiones religiosas y reservas estatales con miras a sedentarizarlos, enseñarles labores agrícolas y transformarlos en mano de obra barata para los asentamientos de colonos

5 Según Censabella (1999: 61), la lengua mbayá de la familia lingüística guaycurú es una lengua extinta. La autora refiere que los caduveo que hablan en la actualidad el caduveo del estado de Mato Grosso do Sul serían sus descendientes.

6 Sobre esta familia, cf. Kalish y Unruh (2004).

7 Esta reconstrucción de las familias lingüísticas y grupos es una actualización de aquella publicada en Tola, Medrano y Cardin (2013) y de una comunicación personal con Rodrigo Villagra (en 2018).

8 Sobre el tema, cf. Osuna (1977), Altamirano, Sbardella y Dellamea de Prieto (1987) y Gordillo y Leguizamón (2002). 
y estancias. ${ }^{9}$ A partir de 1940 comenzó, en el Chaco argentino, un proceso de evangelización y fundación de misiones. Evangelio es la forma en la que los qom denominan a esta expresión religiosa que conjuga elementos del cristianismo pentecostal con aspectos de la cosmología y del chamanismo indígena (Miller 1979; Wright 1992; Ceriani Cernadas 2017). La labor de todos ellos fue central en la sedentarización de los indígenas: los misioneros impulsaron el desarrollo de la agricultura y la economía familiar y fundaron colonias agrícolas en las márgenes de los territorios colonizados. A partir de la acción de los misioneros, fueron surgiendo por todo el Chaco argentino iglesias indígenas alrededor de líderes indígenas que se convirtieron en pastores.

Varios especialistas coinciden en que la ubicación actual de los qom es resultado del avance de las tropas desde el este de Formosa. Tras los sucesivos ataques militares, la penetración ganadera, la reducción de los espacios vitales y la explotación a la que eran sometidos los indígenas chaqueños en los ingenios y obrajes, comenzó hacia 1920 un período de proliferación de evangelizadores y misiones (Miller 1979; Wright 1992, 2008). Así, la sedentarización de estos cazadores-recolectores se fue produciendo no solo alrededor de colonias agrícolas situadas en las márgenes de los territorios colonizados por los criollos para la explotación agrícola y algodonera, sino también en torno a las misiones que impulsaban el desarrollo de la agricultura. Si bien las misiones crearon lugares de refugio y salvaguarda para los indígenas, también conllevaron tensiones y formas de violencia (Miller 1979; Wright 2008; Ceriani Cernadas y Lavazza 2013).

Hoy en día, los tobas, cuya población ronda en las 126.000 personas, ${ }^{10}$ viven en comunidades rurales en el Gran Chaco o en barrios ubicados en los márgenes de grandes urbes (Buenos Aires, Santa Fe, Rosario, Resistencia, Formosa). Los que aún residen en regiones de su antiguo territorio no viven exclusivamente del monte y sus recursos, ya que la expoliación territorial, la sedentarización y la colonización condicionaron su acceso a los antiguos lugares de caza, pesca o recolección. Recientemente, diversos procesos reivindicativos determinaron que los indígenas renovaran sus reclamos por estos territorios que antiguamente se articulaban entre sí a través de recorridos estacionales.

9 Existe una abundante bibliografía regional acerca del impacto en la consciencia colectiva de los pueblos chaqueños del proceso de misionarización. Tanto antropólogos como misioneros se han interesado por las relaciones entre las cosmologías chaqueñas y el evangelismo, así como por el proceso de creación de las diferentes iglesias indígenas. Sobre el tema, cf. Reyburn (1954), Loewen, Buckwalter y Kratz (1997 [1965]), Miller (1979), Ceriani Cernadas (2004, 2014), Wright (2002, 2008), entre otros. Cabe destacar que, tal como refiere Wright, fue el trabajo pionero de Miller en 1967 el que abrió "un espacio conceptual para el análisis de los fenómenos socio-religiosos de la región del Gran Chaco, hasta el momento poco o casi nada explorados" (Wright 2002: 44).

10 Datos del Censo 2010, Instituto Nacional de Estadística y Censos de la República Argentina, desde < https://www.indec.gob.ar > (última consulta en junio de 2019). 
La campaña militar del Gran Chaco y la sucesión de acontecimientos durante la misma es recordada por numerosos ancianos que refieren a ella como "La Guerra". Durante La Guerra, varios indígenas fueron hechos cautivos, asesinados, torturados o trasladados lejos de sus territorios con el fin de ser utilizados para trabajos domésticos y mano de obra esclava. Lo vivido durante La Guerra emprendida por los huataxanaqpi ("militares", "policías") contra los indígenas fue trasmitido de generación en generación hasta el día de hoy. Numerosos adultos refieren en la actualidad acontecimientos que sus antepasados les contaron por haberlos vivido o por haberlos escuchado de otros. A lo largo de la zona central del Chaco argentino he podido registrar entre 2008 y la actualidad algunos de estos relatos y reconstruir así las vivencias de algunos subgrupos que poblaban la región en los años previos e inmediatamente posteriores a la Conquista. Gran parte de estas historias describe la violencia ejercida por los militares, el modo en que fueron asesinados, privados de sus tierras, robados sus niños y violadas sus mujeres. ${ }^{11}$

En este punto, cabe aclarar que nos diferenciamos de las perspectivas que en el Gran Chaco se interesaron por analizar tanto la influencia del capitalismo en los pueblos indígenas (N. Iñigo Carrera 1979, 1983; Trinchero, Piccinini y Gordillo 1992; Gordillo 2004, 2006, 2010; Renshaw 2002), como la historia de las relaciones interétnicas a partir de una perspectiva del Estado y de la Historia (V. Iñigo Carrera 2008; Cardin 2009, 2013). En las últimas décadas, la antropología de la región renovó el interés por las dimensiones históricas de las sociedades indígenas y por las investigaciones etnohistóricas, ${ }^{12}$ y se interesó también por las luchas reivindicativas de la identidad y el territorio, dando cuenta del rol activo de los indígenas en ellas (Carrasco 2009; Salamanca 201 1). Asimismo, la etnografía chaqueña clásica y contemporánea

11 Dichos relatos son, específicamente, parte de la memoria de adultos y ancianos qom de Riacho de Oro, San Carlos, Santo Domingo y Km 503, en donde realizo trabajo etnográfico desde hace 20 años. En estas comunidades he llevado adelante investigaciones con diversos equipos de colaboradores indígenas y académicos, en el marco de proyectos financiados por el Conicet (PIP 0612), la Secretaría de Ciencia y Técnica (PICT 1303, PICT 2757) y la UNESCO (n. ${ }^{\circ}$ 049). La metodología implementada para el registro de la historicidad de los qom de esta región incluyó el relevamiento del territorio reconocido como propio, de la toponimia y los relatos asociados a cada sitio nombrado, de la red parental de más de 1500 personas junto con historias de familias, parejas y personas. Gran parte de estas historias, así como las que acompañan la toponimia, fueron grabadas en qom laqtac (lengua toba) y luego traducidas con la colaboración de hablantes nativos. Parte del material recopilado y de los mapas realizados de modo colaborativo fue presentado en informes técnicos a las comunidades, que disponen de ellos para sus reclamos territoriales ante el Estado provincial. Agradezco la colaboración de mi colega Celeste Medrano, con quien he realizado gran parte de dichas investigaciones entre 2010 y el presente, y de Valentín Suarez, líder qom, con quien trabajamos desde el 2008 de modo colaborativo en diversos proyectos de investigación.

12 Cf. Cordeu et al. (s. d.), Wright (2008), Ceriani Cernadas (2008a), Richard (2008, 201 1), Villar y Combès (2012), Tola, Medrano y Cardin (2013), Sendón y Villar (2013), Messineo (2014), Córdoba, Bossert y Richard (2015), entre otros. 
hace referencia a las entidades no-humanas en diversos momentos y prácticas a lo largo del devenir histórico regional (en las guerras, la Conquista, la evangelización, los obrajes, el chamanismo y en la cacería). ${ }^{13}$ A pesar de algunas excepciones (Wright 2002, 2008), varios de estos trabajos tomaron a las personas no-humanas como deidades o teofanías de una religión chamánica o parte del telón de fondo sobre el que los protagonistas centrales de la historia regional (indígenas, militares, misioneros y colonizadores) llevaban adelante sus interacciones. Si bien la presencia no-humana se encuentra referida en gran parte de la literatura regional, el presente artículo se propone mostrar que estas entidades no fueron exclusivamente parte de un telón de fondo, sino que, desde el punto de vista indígena, ellas ocuparon y ocupan una posición central, activa, actante e intencional en la manera en que los qom modularon, relatan y viven el paso del tiempo y su historicidad.

Por otro lado, la "memoria histórica" de los qom no se reduce a las relaciones que ellos o sus antepasados sostuvieron con la sociedad no-indígena en diversos momentos de sus interacciones. ${ }^{14} \mathrm{Su}$ historia no es solo "la historia

13 Cf. Cordeu (1969-1970), Tomasini (1969-1970, 1978-1979), Miller (1979), Wright (2008), Gordillo (2006, 2010), Ceriani Cernadas (2008a, 2008b), Citro (2009), López (2007, 2013), López y Giménez Benítez (2008, 2009a, 2009b), Medrano (2012), entre otros.

14 A partir de la década de 1990 comenzaron a proliferar en la antropología de pueblos indígenas sudamericanos investigaciones sobre historia-historias, temporalidad, mito-historia, memoria histórica e historicidad. El dossier publicado en L'Homme (1993), editado por Descola y Taylor, está dedicado a la Amazonía y agrupa artículos de los más destacados americanistas que, en Europa, renovaron los estudios sobre sociedades indígenas. En la introducción, Descola y Taylor destacan algunas categorías y dominios hasta el momento no considerados, entre los que está el tema del cambio ya no pensado "desde el punto de vista del etnocidio o la aculturación, sino a partir de la construcción de formas originales de etnicidad y de expresión política” (Descola y Taylor 1993: 21). A finales de 1980, Hill había ya publicado la compilación en la que se adentraba de lleno en el tema de la historicidad, a partir del debate mito-historia, surgido de la distinción de Lévi-Strauss entre sociedades frías y calientes. Inspirados en el análisis de narrativas, rituales y oratorias amazónicas y andinas, los autores compilados por él retoman el interés por la historia, distanciándose de las preocupaciones por las estructuras político-económicas de dominación (Hill 1988: 2), y centrándose en las historias locales y regionales. La "agencia socio-histórica" (Hill 1988: 2) de los sujetos involucrados va a constituir uno de los temas centrales a ser tematizados por las diversas contribuciones, en un intento por discutir la lectura supuestamente a-histórica de la antropología francesa estructuralista. Siguiendo con los debates derivados de las lecturas lévi-straussianas, en 2001 Gow publica An Amazonian Myth and Its History, con la intención de mostrar, a través de su etnografía entre los piro de la Amazonía peruana, la idea lévi-straussiana de que los mitos son "objetos históricos"; idea que se trasluce en su monumental obra de las Mitológicas. En síntesis, las reflexiones lévi-straussianas sobre la historia amerindia dieron lugar a posicionamientos de lo más diversos: unos cuestionan los análisis sincrónicos y formales del estructuralismo (Hill 1988) para repensar la acción histórica y política, mientras que otros se distancian de los enfoques africanistas-ingleses sobre tiempo, para repensar los regímenes de historicidad desarrollados por los pueblos amerindios (Fausto y Heckenberger 2007). Ahora bien, a pesar de sus diferencias, los autores agrupados en ambas compilaciones comparten, por un lado, el interés por la memoria y la temporalidad indígena y, por otro, abandonaron el estudio de la macro-historia, los enormes intervalos, las estructuras de dominación y las nociones de aculturación en pos de la historia en devenir, las filosofías [continua] 
de los pueblos indígenas" luego de su vinculación con los agentes que permitieron la formación del Estado. Su "historia indígena" guarda relación con la modalidad narrativa propia de esta sociedad indígena, en la que no se disocian ni los hechos sucedidos durante la Conquista y colonización de aquellos ocurridos en los primeros tiempos ("los tiempos de los antiguos"), ni el accionar de los sujetos humanos del de otras entidades que también son pensadas como sujetos. Los relatos que describen momentos traumáticos para los indígenas están también plagados de seres no-humanos que desempeñaron un papel crucial en el devenir histórico qom. Muchas narraciones describen el modo en que los indígenas lograron escapar y vencer gracias a la comunicación entablada con entidades que los socorrieron y se aliaron con ellos en contra de sus enemigos.

Dentro del repertorio del arte verbal qom, tal como el trabajo de los lingüistas da cuenta (Messineo 2003, 2014), tanto las historias míticas como los relatos históricos forman parte del género narrativo, cuyos relatos fueron transmitidos oralmente de generación en generación. En palabras de la autora:

"La narrativa constituye una práctica comunicativa relevante en la vida social de los tobas. La tipología de relatos que incluye narraciones míticas, cuentos humorísticos del zorro, historias de vida y crónicas de sucesos históricos, entre otras, provee un amplio panorama respecto de la historia, la cosmovisión, la ecología, las relaciones sociales y las normas éticas y morales del grupo" (Messineo 2003: 200).

La autora continúa diciendo que "todas las narraciones - sean míticas, históricas o personales - presentan una estructura discursiva casi idéntica y utilizan recursos retóricos y morfosintácticos similares" (Messineo 2003: 201). Tal como se aprecia en los relatos que hemos registrado, los sucesos que narran varios relatos "históricos" de los qom están insertos en una socio-cosmología y en una ontología que tienen implícitas una noción particular de agencia, de transformación y de persona: gran parte de ellos entrelaza el accionar de los caciques memorables y las batallas con el ejército, con el obrar de entidades que son consideradas personas capaces de incidir en la vida de los seres humanos, en el transcurso de la historia y en el mundo. Lo relatado por los ancianos, que recuerdan lo que sus padres y abuelos les contaron, sobre la conquista no se limita a las atrocidades cometidas por el ejército o a las hazañas y estrategias de líderes y guerreros indígenas, sino que describe los

sociales de la temporalidad, las transformaciones, los regímenes de historicidad, la agencia y la acción creativa humana (Fausto y Heckenberger 2007). Para el caso de los qom, existen trabajos pioneros sobre el tema: Miller (1979), Cordeu (1969-1970), P. Vuoto y Wright (1991), Gordillo (2005) e Idoyaga Molina (1992, 1994), entre otros. 
poderes y las visiones de chamanes, animales, pájaros, muertos y dueños de animales. ${ }^{15}$ Como refieren Fausto y Heckenberger para la Amazonía, la "historia indígena" es "el resultado de interacciones sociocósmicas entre diferentes tipos de personas, humanas y no-humanas [...]" (2007: 14, subrayado nuestro). Si bien entendemos que lo social y lo cósmico no se hallan diferenciados en la ontología qom, pues todas las entidades del cosmos poseen una existencia social, consideramos pertinente esta aseveración que, aunque provenga de otra zona de las tierras bajas sudamericanas, nos permite ampliar el foco de nuestro análisis y contemplar que, entre otros pueblos indígenas sudamericanos, la historia fue también estudiada como la consecuencia del accionar intencional de personas no solo humanas.

Veamos algunos relatos o fragmentos de historias. ${ }^{16}$ Según lo relatado por el anciano qom Rachiyi, ya fallecido, a su nieto Valentín Suarez - líder actual de la zona central de Formosa -, toda su "raza" (subgrupo) se salvó gracias al accionar de una mujer que podía comunicarse con el sapo. Cuando Rachiyi era niño, el ejército hizo subir a mujeres y niños a un barco para ser trasladados por el río Bermejo y los hombres eran conducidos por la costa del río a la vera de la embarcación, custodiados por un militar. Según Rachiyi, los indígenas caminaron durante varios días hasta llegar a un "campo de concentración" - en palabras de Valentín - situado a orillas del río y denominado en toba Qaiua$x a^{\prime} a \tilde{n} i$. Este lugar es ubicado por los ancianos cerca del actual emplazamiento de El Espinillo y su nombre hace referencia a los palos clavados en el suelo donde los cautivos fueron amarrados luego de padecer hambre, sed y maltratos corporales. Esta situación cambió gracias a una mujer que era una reconocida conaxanaxae; término que si bien suele ser traducido como "bruja", remite más particularmente a la "agarradora" (aquella que realiza la acción referida por la raíz verbal -cona-: "agarrar"). ${ }^{17}$ En el relato de Valentín, la conaxanaxae sugirió a los qom que juntaran las colillas de los cigarrillos que fumaban los militares. Los qom así hicieron y, una vez reunidas las colillas, en palabras de Valentín,

"[se] las dieron a ella. Después, un momento hubo en la noche que descansaban los soldados y ellos [los qom] tuvieron la libertad de hacer un fuego.

15 Es abundante la literatura chaqueña que refiere al rol central desempeñado por las aves en la comunicación con los chamanes y los oiquiaxai. Durante la Conquista, numerosos chamanes lograron huir del invasor gracias a los mensajes que los pájaros les enviaban. Sobre el tema, cf. Miller (1979), Balducci (1982), Wright (2008), Medrano (2012, 2013), Tola y Suarez (2016), entre otros.

16 Algunas de las historias aquí editadas fueron presentadas en una ponencia colectiva (Medrano, Tola y Suarez 2016).

17 Sobre las prácticas de brujería y el accionar de las brujas, existen diversas lecturas e interpretaciones en la literatura regional: cf. Salamanca y Tola (2002), Karsten (1932), Palavecino (1935), Reyburn (1954), Métraux (1967), Cordeu (1969-1970), Martínez Crovetto (1975), Miller (1979), Idoyaga Molina (2000) y Salamanca y Tola (2002). 
Y ella le dice a la gente que haga fuego y, en ese momento, apareció un sapo, un sapo grande, gigante. Ese sapo trabajaba con ella. Lo agarró $[\ldots]$ y las colillas de cigarrillo metió en la boca de ese sapo [...]. O sea que le metió en la boca hasta que todo se fue a la panza del sapo. Y [...] ella decía que iba a tirar al fuego a ese sapo con todas las colillas de cigarrillo [adentro]. Después dice ella: 'si se revienta el sapo [es] porque algo va a ocurrir', venganza hacia los soldados, hacía los que fumaban esos cigarrillos".

El sapo reventó y la venganza fue exitosa: al día siguiente, los soldados comenzaron a sentir malestar, dolores, estados de somnolencia y decaimiento generalizado. Por la noche, con la tropa devastada por los efectos de la acción de la venganza, los qom lograron escapar y regresar a sus lugares de origen. La conaxanaxae, el fuego y el sapo son los actores que, en este episodio, cambiaron el rumbo de la historia de los qom. Tanto esta mujer con poderes de comunicación con otras entidades, como el fuego y el sapo fueron necesarios para derrotar al ejército y para que los qom continuaran con vida.

Varios son los relatos como este que dan cuenta del modo en que los no-humanos incidieron en el devenir de la historicidad chaqueña, al ayudar, aliarse, aconsejar u orientar a los tobas que eran perseguidos. Esto se lee también en otra narración que refiere a este mismo período y que nos fue relatada por un anciano de la comunidad Dañalec lachiugue (Riacho de Oro). En ella, se escucha acerca del modo en que varias mujeres tobas, capturadas por el ejército, emprendieron la huida ayudadas por un ser del cielo. Según refiere el narrador, una anciana y cinco jóvenes que se habían alejado de la comunidad para recolectar frutos de algarroba (Prosopis spp.) desaparecieron. Luego, se supo que habían sido secuestradas por los militares quienes las hicieron cautivas, las maniataron y las condujeron a pie hacia el sur. Los militares, montados en burros o a caballo, las obligaron a marchar "tres qa'agoxoic [lunas]" ${ }^{18}$ hasta llegar a un nuevo "campo de concentración". Cuando arribaron, allí había una construcción de madera y un cepo en el que las prisioneras fueron amarradas. Sin embargo, una de las jóvenes tenía la capacidad de "comunicación con Qasoxonaxa", tal como dice su narrador, y gracias a esta relación la historia pudo ser contada. Qasoxonaxa es el nombre que se le da a un ser no-humano del cielo que tiene la capacidad de controlar los fenómenos climáticos, principalmente, la lluvia, el trueno y el rayo. Una mañana, esta joven recibió un mensaje de esta entidad en el que le comunicaba que esa noche debían escapar. Según lo referido a nuestra compañera de trabajo de campo, Celeste Medrano:

18 En Buckwalter y Buckwalter (2001: 5), el término para "luna" es escrito del siguiente modo: ca'agoxoic. Las diferencias entre la -c- y la -q-inicial puede deberse al modo diferente en que los hablantes tobas de diversas regiones pronuncian un mismo lexema. 
“Dice que llegó esa noche se armó la lluvia. Los militares estaban refugiados adentro de los buenos edificios y ellas en el campo de concentración. Cuando llovió mucho, los rayos caían y se aflojaron los postes. Había una abertura por la que ellas podían salir y escapar. Van dirigidas hacia el norte. Y la viejita, la anciana se quedó [por no poder emprender el camino de regreso]. Y bueno, caminaron meses y meses de noche en la selva, en el campo, en el monte. Las mujeres se subían a los árboles porque había mucho tigre en ese entonces. [...] Pasaron tres qa'agoxoi otra vez y ellas pudieron llegar al lugar de destino." [comunicación personal]

Esta capacidad de relacionarse con animales, plantas y fenómenos atmosféricos que "agarradoras" y otras personas tenían en el pasado era también un atributo propio de los antiguos líderes denominados oiquiaxai. Estos eran jefes en las épocas de guerra y desempeñaron un papel protagónico durante la Conquista militar. Según Miller, los oiquiaxai eran "personas con poderes excepcionales para comunicarse con los espíritus de los muertos poderosos" (1979: 103). En efecto, gracias a los diálogos de los oiquiaxai con los pájaros y los astros (no solo con los muertos), ellos lograron, en palabras de un líder qom, conducir "a la tribu en tiempos de guerra".

En diversos momentos de la historia chaqueña, militares e indígenas fueron activos protagonistas que, luchando, resistiendo o atacando, dieron lugar al panorama étnico, histórico y territorial contemporáneo. Sin embargo, ellos no fueron los únicos actores de esta historia. En momentos particulares como las insurrecciones, las huidas, las relocalizaciones o el cautiverio, los seres no-humanos desempeñaron un papel que los mismos tobas resaltan en la mayoría de sus relatos sobre este período. Dueños de animales, astros, sapos, aves y fuego son algunos de los personajes de dichas narraciones que constituyen el ensamblaje humano-no-humano que compone la vida en común para los qom: una vida en común que se desenvuelve en un entorno modelado topográficamente también por estos seres no-humanos.

\section{HUELLAS EN EL ENTORNO}

Las acciones pasadas y actuales de los no-humanos dejan trazos en el "monte" (término genérico con el cual se refieren al bosque chaqueño), ya sea como fruto de su interacción con los humanos, ya sea como consecuencia de sus acciones, independientes de los humanos. En el monte, por ejemplo, es factible encontrar piedras negras de la época antigua (mítica, diríamos nosotros) en la que por la tierra pasó el gran fuego (norecalo), ${ }^{19}$ montículos de tierra debajo 
de los cuales vive el padre de las víboras (qomonaxalo), que se enoja cada vez que huele sangre menstrual y hongos, que son en realidad el excremento de la dueña del rayo, representada como un elefante (qasoxonaxa). Se hallan también zonas con abundantes bromelias que esconden la morada subterránea de pequeñas mujeres del monte, llamadas huashole', y caracoles rotos que son la piel abandonada de la dueña de las víboras ('araxanaq late'e). Asimismo, es posible oír a los diversos seres no-humanos en su despliegue por el monte y por las comunidades. Los muertos y los habitantes de abajo del agua se hacen oír cada vez que lavan sus ollas, que ríen o que usan los objetos de los vivos presentes en sus viviendas.

Además de estos signos visibles y audibles de entidades otras, la extensa toponimia chaqueña muestra también los efectos de los seres no-humanos en la geografía qom. Varios autores han demostrado a partir de sus etnografías en el Gran Chaco y en otras latitudes ${ }^{20}$ que en las sociedades cazadoras-recolectoras el territorio es nombrado en función de las características topográficas y de aquellas que remiten a la presencia de especies animales y vegetales, así como de los acontecimientos que fueron significativos en la historia de los grupos que crean y transmiten los topónimos. De hecho, los nombres de los lugares y las historias que los fueron constituyendo son transmitidos de generación en generación estableciéndose, de este modo, continuidades entre los acontecimientos vividos por los antepasados y la identidad y las prácticas de los grupos actuales. En su trabajo sobre las denominaciones toponímicas y etnonímicas de los tobas, la lingüista argentina Marisa Censabella refiere que los topónimos de este grupo están mayoritariamente formados por "un nombre derivado, un nombre compuesto o un sintagma nominal” (2009: 224). A partir de un análisis lexical y morfológico, Censabella organiza los topónimos obtenidos tanto de fuentes escritas desde mediados del siglo XVIII hasta finales del siglo XX, como de sus informantes del noreste de la provincia de Chaco, de la siguiente manera: (a) lugares tradicionales de asentamiento (lagunas y esteros); (b) enclaves donde los "nuevos toba" se relocalizaron entre finales del siglo XIX y primeras décadas del Xx; (c) lugares cuyo nombre remite a las características topográficas (lugares de paso o ríos); (d) cotos de caza; (e) lugares de paso y en los que ocurrieron "hechos históricos o hechos de carácter sobrenatural" (Censabella 2009: 228). Contrariamente a los anteriores, estos últimos requieren - según la autora - una contextualización por parte de los narradores, ya que su nombre no suele ser transparente. Esta sistematización se asemeja a la ya nía, cabe destacar los siguientes trabajos tanto en el Chaco argentino como en otras regiones sudamericanas: Miller (1973), Wright y Braunstein (1990), Wright (1990), Braunstein (1993), Palmer (1995, 1997), Fernández y Braunstein (2001), Salamanca (2006), Censabella (2009), Descola (1986), Surrallés (2003), entre otros. 
propuesta por los antropólogos argentinos Analía Fernández y José Braunstein (2001) para los tobas de Pampa del Indio (provincia de Chaco). ${ }^{21}$

Al recordar el pasado de su subgrupo, los ancianos con quienes trabajé refieren a una gran variedad de nombres de lugares por los que transitaban y en donde residían sus antepasados. Muchos de estos nombres reflejan los conocimientos ecológicos de los tobas - huoiem lae' (donde abunda el mono); qarol lae' (donde abunda el bagre); relliquic lapel (laguna de palo santo); euaxai lamo (nacimiento del [río] salado) -. Otros nombres remiten a hechos particulares vividos por algún miembro del grupo - Chingolo lche' (la pierna de Chingolo) refiere a la historia del pescador llamado Chingolo a quién un pez de esa laguna le mordió la pierna; araxanaxaqui (mortero), allí donde antiguamente las mujeres toba se juntaban a macerar frutos con sus morteros -. Otros nombres condensan historias vividas por los antiguos antes, durante y después de los enfrentamientos con el ejército por los años de la conquista chaqueña: Roqshe nalleuo (el blanco miró), por ejemplo, alude a la llegada del ejército al estero donde se encontraba el campamento; 'eraxai (luciérnaga) designa un monte tupido al que llegaron los toba que escapaban del ejército y que iluminaban el camino con estos insectos. Qo'oxoi es el nombre de otro sitio cuya historia consiste en que durante la conquista del Chaco un chamán fue advertido por su compañero no-humano de cavar una zanja para esconder a su grupo. Sin embargo, el ejército los encontró y los fusiló a todos. Finalmente, otro conjunto importante de nombres refiere a las acciones de seres no-humanos que incidieron en la vida y permanencia de los tobas en ese lugar. Este es el caso de lashe n'naxaganaxaqui (laguna del bicho del agua), en la que ocurrió una catástrofe luego de que una joven que menstruaba se acercó a la laguna, enojando así a las personas no-humanas, que sienten repulsión por el olor de la sangre menstrual. La historia de huoqauo' lae' tiene como protagonistas ya no al ejército ni a los qom, sino a pájaros-personas que, sintiendo compasión de los humanos, le avisaron al chamán del grupo que en la laguna donde ellos estaban podían encontrar abundantes peces. Tal como estos pocos ejemplos muestran y la abundante bibliografía demuestra, la extensa toponimia chaqueña es un libro escrito en el territorio que cuenta sobre hechos significativos del pasado de cada subgrupo, del entramado de las relaciones parentales, así como de las relaciones con los seres no-humanos.

21 La clasificación de Fernández y Braunstein (2001) es la siguiente: (a) lugares de habitación o campamento (relacionados con fuentes de agua); (b) lugares de actividades económico-productivas (referencia a las especies animales y vegetales que se encontraban allí y a alguna característica física del lugar): (c) lugares preestablecidos de encuentro entre grupos; (d) puntos intermedios o etapas de itinerarios usuales; (e) sitios donde ocurrieron hechos históricos y extraordinarios; (f) lugares que funcionan como límites geográficos-territoriales. 


\section{INFLUENCIAS EN EL CUERPO: REFLEXIONES FINALES SOBRE}

\section{LA ONTOLOGÍA QOM}

En las manifestaciones corporales que la persona va adoptando a lo largo de su vida juega un papel central la agencia, no solo de los seres humanos, sino también de los no-humanos. El cuerpo-persona es susceptible de transformarse a raíz de la acción de entidades no-humanas que dejan marcas en él e inciden en su apariencia. Una persona-cuerpo puede combinar elementos y aptitudes tanto humanas como no-humanas, ya que, tal como desarrollamos en trabajos previos (Tola 2012), el cuerpo no contiene siempre a los elementos que hacen a la persona ni las personas están contenidas exclusivamente dentro del cuerpo. Existen, de hecho, componentes (fluidos corporales, nombres, sombra, etc.) que pueden desterritorializarse; alejarse momentáneamente del cuerpo y permitir la fusión de cuerpos-personas humanas y no-humanas. ${ }^{22}$ Nauoxa es el término que sintetiza las consecuencias que padece la persona-cuerpo humana al no respetar las reglas de comportamiento que rigen las relaciones con los no-humanos en momentos especiales de la formación y transformación del cuerpo. Algunos qom traducen nauoxa (-uoxa: raíz del verbo "hacer mal”) como "contagio", en su intento por referirse al proceso de transmisión de las características formales o de comportamiento entre entidades diversas. Un toba tradujo este término como "imitación”, refiriéndose a la semejanza entre la entidad humana y la no-humana luego de un momento de cercanía excesiva entre ambos. Y otro joven, intentando transmitir la amplitud del fenómeno nauoxa, utilizó el término "influencia”. La idea de la influencia da más cuenta del proceso implicado. Según su reflexión, "influencia” remite al proceso que se lleva a cabo entre dos seres que "cruzaron sus caminos" y que se dejaron una huella en su constitución corporal-vital. Esta huella es vivida como una

22 Existen en el Chaco argentino trabajos antropológicos que, desde los comienzos de la etnografía chaqueña, se dedicaron a la temática del cuerpo. Uno de los referentes en la temática del cuerpo es la antropóloga Silvia Citro (2000) quien, retoma la perspectiva de Wright sobre el Evangelio y conjuga la dimensión "numinosa" con ciertas experiencias extáticas de los cultos pentecostales para explorar la dimensión corporal de dichos cultos y las formas que estos adoptan en tanto ritual, en el marco de relaciones interétnicas de dominación y resistencia. Sus trabajos dialogan con la sociología francesa centrada en las inscripciones del poder en el cuerpo y el concepto fenomenológico de embodiment. La reflexión sobre el cuerpo como lugar de inscripción del poder, tanto en los contextos rituales evangélicos como en la vida cotidiana, permite a Citro poner en relación la antropología fenomenológica con aquella centrada en las relaciones de subordinación. Más recientemente, Citro (2009, 2011) se interesó por efectuar una antropología dialéctica de y desde los cuerpos que integre tanto la cuestión de la corporalidad entre los qom como sus propias experiencias corporales, en tanto etnógrafa. En permanente diálogo con la perspectiva fenomenológica de Merleau-Ponty, Citro sugiere que "habría una experiencia fenomenológica de la carne común a diferentes culturas, la cual, no obstante, ha sido más visible en determinados contextos culturales [...] mientras habría sido invisibilizada en las prácticas y las representaciones occidentales que han sido hegemónicas hasta la modernidad..." (201 1: 41). 
influencia susceptible de transformar el régimen corporal, los comportamientos y la personalidad de las dos personas implicadas.

Trataremos de ilustrar esto con una anécdota ocurrida durante los comienzos de mi trabajo de campo. Junto con una colega que trabajaba en el barrio toba, fuimos a visitar a una joven que, luego de intercambiar algunas palabras, nos expresó su angustia por el estado de salud de su hijo, que había amanecido con decaimiento y manchas negras que ella atribuía a la acción de ciertas entidades no-humanas: los pel'ec (personas de la noche). Al tocar el cuerpo humano, estas personas no-humanas dejan manchas del mismo color del cuerpo que ellos tienen. Asimismo, los pel'ec son susceptibles de obrar de acuerdo a lo que los chamanes les piden y atacar a quien le indiquen. Comencé a hablar con la mujer sobre la dolencia de su hijo, sobre las posibles personas que desearían lastimarla, sobre el hecho de que los chamanes atacan a los más vulnerables y sobre las características corporales de los pel'ec. Al salir de allí, mi colega, que había estado en silencio durante toda la conversación, me preguntó cómo podía mantener ese diálogo con la mujer toba acerca de temas en los que seguramente yo no creía. Le contesté que, en mi opinión, no se trataba de creer o no en los pel'ec o en los ataques chamánicos, sino en mantener con mis interlocutores una conversación sobre los temas y problemas que para ellos eran importantes en sus vidas; en síntesis, poder crear una relación a pesar de las diferencias que nos atraviesan, diferencias que no me interesaba minimizar en pos de una búsqueda pseudo-antidiscriminatoria de los elementos que nos vuelven semejantes, que nos acercan como seres humanos o que hacen de los "otros" un nosotros. Sin embargo, mi preocupación por la alteridad no constituía tampoco una búsqueda en los escombros de una cosmología perdida, de una manera ya inexistente de vivir o de una ontología que solo los chamanes conocen. Si bien los chamanes tobas poseen capacidades de metamorfosis, de desplazamiento y de comunicación con seres no-humanos y son, a su vez, capaces de relatar sus vivencias en otros mundos a los seres humanos, ciertas capacidades (como aquella de percepción cambiante, de soñar, de ser afectado por un no-humano o de afectar a otros seres con el pensamiento y la simple intencionalidad) no son exclusivas de ellos y pueden ser consideradas como potencialidades de todos los seres humanos. A nuestro entender, el principio de transformación de la realidad y de la percepción cambiante de todo ser considerado persona constituyen pilares de una filosofía no-esencialista en la que el mundo y sus singularidades presentan potencialidades metamórficas, perceptibles para los otros, según los contextos de comunicación e interacción. ${ }^{23}$

23 En su texto clásico, Viveiros de Castro refiere al lugar central de los chamanes (aunque no menciona que el perspectivismo sea una filosofía pura y exclusivamente de los chamanes amazónicos), a quienes define como "mestres do esquematismo cósmico [...], dedicados a comunicar e administrar essas perspectivas cruzadas, estão sempre aí para tornar sensíveis os conceitos ou tornar inteligíveis as intuições" (Castro 1996: 117). Es decir, si el perspectivismo se manifiesta en sociedades con [continua] 
Ahora bien, la pregunta por la creencia y la honestidad de nuestro posicionamiento en el trabajo de campo, ante aquello que contrasta con nuestras propias "creencias", no era una pregunta insignificante. Si bien mi respuesta me permitía continuar con mi trabajo, sin duda era una pregunta que me confrontaba con una de las consecuencias ontológicas de la confrontación con la alteridad. "Tomar en serio" lo que los qom dicen sobre los seres no-humanos que, tras su accionar, inciden en la forma y características del cuerpo-persona y el entorno, y que definen también la historicidad de los pueblos indígenas, significa no tanto creer en el universo en el que los tobas - más que creer están inmersos, sino tomarlo como otro mundo posible. ${ }^{24}$ Para acceder a él, situaciones como la descrita son la vía de acceso a la ontología de otros colectivos, entendiendo por ontología los principios que subyacen a las maneras de imaginar un mundo, sus constituyentes y las relaciones entre estos (cf. Descola 2005, 2014), más que las representaciones, cosmovisiones o creencias que los "otros" poseen.

Tomamos la definición de ontología de los desarrollos de la antropología americanista (más que nada francesa y brasileña) de los últimos 30 años. Esta elección no desconoce la existencia de una antropología chaqueña que, desde los años 60, tiene a la ontología, a la mitología y a la religión como sus pilares centrales de indagación (cf. Bórmida 1969, 1973, 1974, 1975, 1976; Wright 2008). Sin embargo, no adherimos ni a la perspectiva de Bórmida sobre la ontología, en la que mito-rito funcionarían como el lugar primordial del estudio de una cultura y de la acción humana, ni a la idea de que la ontología sea, en el caso de los pueblos indígenas, "la inquisición acerca de la naturaleza de la realidad" (Wright 2008: 33). En el Chaco paraguayo, quizás sean las investigaciones sobre ontología, política y no-humanidad de Blaser $(2009,2013,2016)$ las que resuenen más con nuestra propuesta. Su perspectiva abreva tanto de la antropología francesa y brasileña como de aquella norteamericana. En sus diversos trabajos, Blaser define "ontología" como el inventario de tipos de seres y sus relaciones posibles, expresa la centralidad de las prácticas que involucran a humanos y a no-humanos, y se interesa por las narraciones de sus interlocutores ishir, pues en ellas se establece lo que existe y las relaciones. Este antropólogo argentino radicado en Canadá sostiene también la centralidad de “tomar

chamanes, con cazadores, con presas y predadores, esto no significa que los únicos humanos que vivan el perspectivismo sean los chamanes.

24 Sobre la noción de "mundo" existe una gran diversidad de posturas antropológicas y filosóficas cuya descripción y detalle excede, por completo, el objetivo de este artículo. Sin embargo, para una lectura del concepto de "mundo" tal como está siendo usado por la antropología ontológicamente orientada, remitirse al dossier especial de $H A U$ (Hanks e Severi 2014) que brinda una pluralidad de lecturas antropológicas críticas sobre el mismo. En el caso del Chaco argentino, ver especialmente los trabajos de Wright (2008), que conjugan un interés por la filosofía existencialista y fenomenológica y la filosofía amerindia en lo referido a la noción de mundo. 
en serio" a los no-humanos y dejar de considerarlos como metáforas de otras realidades. Su interés por la ontología lo condujo a una preocupación política y a centrarse en lo que él define como "ontología política". En la medida en que los mundos son siempre el ensamblaje heterogéneo de humanos y no-humanos, Blaser se pregunta: ¿qué es la política en estos ensamblajes que rompen con las dicotomías a las que estamos acostumbrados? Retoma la proposición cosmopolítica de Isabelle Stengers (2005) y expresa que, cuando los no-humanos no son concebidos como fruto de la imaginación, ellos entran en la escena política de nuestros interlocutores y, desde este punto de vista, ameritan ser tomados en serio. Blaser retoma la propuesta de Descola precisamente porque el antropólogo francés muestra la existencia de múltiples ontologías y porque da cuenta de que la ontología moderna es una entre otras que distribuye lo que existe de una forma diferente. Su interés será abordar este pluralismo ontológico desde los conflictos medioambientales, que serán leídos como verdaderos conflictos ontológicos ya que activan diversas formas de enactuar el mundo.

Ahora bien, cabe aclarar que el giro ontológico en antropología no constituye una corriente homogénea ni todos los antropólogos adoptan, en esta tendencia, una misma definición de ontología. Sin embargo, a pesar de las variaciones, varios de los trabajos de esta línea con los cuales decidimos dialogar se interesan por incorporar a más que humanos (more than human), no-humanos, híbridos y transespecies, en una tendencia que ha sido considerada posthumanista (cf. Kohn 2012, 2013). De hecho, el cuestionamiento de la "gran división" como matriz universal y las etnografías que mostraron el papel central de la relación con los no-humanos en otras maneras de componer el mundo dieron lugar a lo que Latour (2012) llama "naturalizaciones alternativas", es decir, modos de concebir la naturaleza que no la reducen a su relación con los humanos, ni la explican necesariamente en términos antropomórficos.

Situaciones como las que describimos a lo largo de este texto son lo que Viveiros de Castro (2004) define como misundestandings, o equívocos, en el sentido de una falla en entender que las undestandings, o comprensiones, no son iguales y que no están relacionadas con formas imaginarias de ver el mundo, sino - como expresa también Blaser - con los mundos reales que son percibidos por diversos colectivos. En palabras de M. Herzfeld: "anthropology is about misunderstandings" (Herzfeld 2001: 2, citado en Castro 2004: 10). Estas ideas antropológicas se anclan sin duda en el perspectivismo y el multinaturalismo amerindio, teorías que postulan que el mundo está compuesto por un conjunto de elementos cuya naturaleza varía de acuerdo al punto de vista del sujeto que percibe, punto de vista que se halla en el cuerpo (Castro 1996). Ya no se trataría de representaciones variables de un único mundo, sino de mundos diferentes. Es decir, todos los “existentes" perciben del mismo modo, o mediante las mismas categorías y valores, y lo que varía es el correlato 
objetivo que ellos ven. ${ }^{25}$ Caza, guerra, comida fermentada, presas y predadores son las categorías de las que se sirven humanos y no-humanos en gran parte de Amazonía, pero para unos la sangre es sangre y para otros es miel, para unos un cadáver es un cadáver y para otros es mandioca fermentada. Tomadas como método antropológico, estas ideas amazónicas acerca de múltiples mundos a ser actualizados - más que un único mundo a ser objetivado por múltiples interpretaciones (culturas) - permitirían un acercamiento a la alteridad entendida como la expresión de puntos de vista plurales sobre mundos que también lo son (cf. Castro 2004).

Ahora bien, ¿qué significa tomar la idea propia del perspectivismo sobre la existencia de múltiples mundos como método antropológico? Tomada como método, la equivocación controlada conceptualizada a partir del perspectivismo amerindio ayuda a percibir las "falsas homonimias", a no dejarse engañar por la semejanza aparente entre nuestra "lengua" o aparato conceptual y el de los sujetos con quienes trabajamos. Lejos de los "sinónimos transculturales" es preciso reconocer que nos encontramos ante puntos de vista plurales sobre mundos plurales.

En síntesis, en este texto nos propusimos reflexionar sobre la idea de que la ontología toba constituye una forma de percibir, de relacionarse y de actuar en el mundo (sin duda mediante el lenguaje también), en el que diversos existentes no-humanos definen el cuerpo-persona, el entorno y el accionar humano a lo largo del tiempo. En determinadas circunstancias y bajo ciertas condiciones, los seres humanos son capaces de comunicarse con los no-humanos y de acceder a la condición de persona de estas entidades, principalmente a través de los trazos dejados por ellas y de los mensajes, que les trasmiten en sueños o mediante aves y otros animales, que los humanos descifran. Es por eso que lejos de tratarse de una cuestión de fe o de una adhesión firme a determinados dogmas, la ontología qom se basa en nociones aprendidas desde la infancia, mediante prácticas discursivas, que expresan que los seres humanos no son los únicos existentes dotados de vida social, cuerpo, intencionalidad e interioridad.

Visto de esta manera, las relaciones que se mantienen con estos otros seres sociales (espíritus, muertos, dueños de animales, fenómenos atmosféricos), más que ser catalogadas como creencias, metáforas, representaciones o nociones espirituales, constituyen, a mi modo de ver, el sustrato mismo de experiencia y de la vida social qom. Si un "análisis antropológico del pluralismo político

25 Utilizo el término "existente" en el sentido que Descola le da al mismo: cualquier cosa de la cual un ser humano piensa que existe, ya sea porque posee una forma material o solamente conceptual [Philippe Descola, comunicación personal]. Asimismo, además de remitir a todo ente que existe, a diferencia del término "ser", "existente" no especifica el modo en que existe aquello que existe. Es decir, un existente puede existir en tanto ser o puede existir en tanto devenir. Esta última idea es acorde con las ontologías amerindias para las cuales la transformación y la porosidad de los límites de cada entidad son características constitutivas de todo lo que existe. 
es incompleto hasta que no tomamos en serio la posibilidad de un pluralismo ontológico" (Di Giminiani 2013: 528, traducción nuestra), la misma advertencia vale cuando intentamos mostrar el pluralismo existente en las maneras de narrar el paso del tiempo, de abordar las nociones de cuerpo-persona y de entorno.

\section{BIBLIOGRAFÍA}

AltAMIRANO, Marcos, Cirilo SBARDElla, y Alba DEllameA DE PRIETO, 1987, Historia del Chaco. Resistencia, Editorial Dione.

BALDUCCI, María Isabel, 1982, Códigos de Comunicación con el Mundo Animal entre los TobaTaksik. Buenos Aires, Facultad de Filosofía y Letras, Universidad de Buenos Aires, tesis de licenciatura inédita.

BLASER, Mario, 2009, "Political ontology: cultural studies without 'cultures'?", Cultural Studies, 23 (5-6): 873-896.

BLASER, Mario, 2013, "Ontological conflicts and the stories of peoples in spite of Europe: toward a conversation on political ontology", Current Anthropology, 54 (5): 547-568.

BLASER, Mario, 2016, "Is another cosmopolitics possible?", Cultural Anthropology, 31 (4): 545-570.

BÓRMIDA, Marcelo, 1969, "Mito y cultura”, Runa, 7: 9-52.

BÓRMIDA, Marcelo, 1973, "Ergon y mito 1: una hermenéutica de la cultura material de los Ayoreo del Chaco Boreal”, Scripta Ethnologica, 1 (1): 9-68.

BÓRMIDA, Marcelo, 1974, “Ergon y mito 2", Scripta Ethnologica, 2 (2): 41-107.

BÓRMIDA, Marcelo, 1975, "Ergon y mito 3", Scripta Ethnologica, 3 (1): 73-130.

BÓRMIDA, Marcelo, 1976, "Ergon y mito 4”, Scripta Ethnologica, 4 (1): 29-44.

BRAUNSTEIN, José, 1983, "Algunos rasgos de la organización social de los indígenas del Gran Chaco", Trabajos de Etnología, 2: 9-102.

BRAUNSTEIN, José, 1993, “Territorio e historia de los narradores matacos”, Hacia Una Nueva Carta Étnica del Gran Chaco, 5: 4-74.

BUCKWALTER, Alberto, y Lois Litwiller de BUCKWALTER, 2001, Vocabulario Toba. Elkhart e Indiana, Equipo Menonita (edición revisada).

CARDIN, Lorena, 2009, "Antiguos reclamos - nuevas estrategias: el actual movimiento sociopolítico toba en Colonia Aborigen La Primavera (Formosa)", presentado en IV Congreso Argentino y Latinoamericano de Antropología Rural (Inta y Nadar). Mar del Plata, Argentina.

CARDIN, Lorena, 2013, "Construcciones en disputa de la identidad qom: la escenificación de las diferencias ante la Corte Suprema de Justicia de la Nación”, en F. Tola, C. Medrano y L. Cardin (comps.), Gran Chaco: Ontologías, Poder, Afectividad. Buenos Aires, Rumbo Sur/ /Ethnographica/IWIGIA, 361-383. 
CARRASCO, Morita, 2009, Tierras Duras: Historias, Organización y Lucha por el Territorio en el Chaco Argentino. Buenos Aires, IWIGIA.

CASTRO, Eduardo Viveiros de, 1996, "Os pronomes cosmológicos e o perspectivismo ameríndio", Mana, 2 (2): 115-144.

CASTRO, Eduardo Viveiros de, 2004, "Perspectival anthropology and the method of controlled equivocation", Tipití: Journal of the Society for the Anthropology of Lowland South America, 2 (1): 3-22.

CAYÓN, Luis, 2018, "Etnografía compartida: algunas reflexiones sobre el trabajo de campo con los makuna en la Amazonía colombiana”, Anales de Antropología, 52 (1): 35-43.

CENSABEllA, Marisa, 1999, Las Lenguas Indígenas de la Argentina: Una Mirada Actual. Buenos Aires, Eudeba.

CENSABELlA, Marisa, 2009, “Denominaciones etnonímicas y toponímicas tobas: introducción a la problemática y análisis lingüístico", Hacia Una Nueva Carta Étnica del Gran Chaco, 8: 213-236.

CERIANI CERNADAS, César, 2004, "Convirtiendo Lamanitas: indagaciones en el mormonismo toba", Alteridades, 12 (25): 121-137.

CERIANI CERNADAS, César, 2008a, Nuestros Hermanos Lamanitas: Indios y Fronteras en la Imaginación Mormona. Buenos Aires, Biblos/Culturalia.

CERIANI CERNADAS, César, 2008b, "Vampiros en el Chaco: rumor, mito y drama entre los toba orientales", Indiana, 25: 27-50.

CERIANI CERNADAS, César, 2014, "Configuraciones de poder en el campo evangélico indígena del Chaco argentino”, Sociedad y Religión, 41 (24): 13-42.

CERIANI CERNADAS, César, 2017, Los Evangelios Chaqueños: Misiones y Estrategias Indígenas en el Siglo XX. Buenos Aires, Rumbo Sur/Ethnographica.

CERIANI CERNADAS, César, y Hugo LAVAZZA, 2013, "Fronteras, espacios y peligros en una misión evangélica indígena en el Chaco argentino (1935-1962)”, Boletín Americanista, 2 (67): 143-162.

CITRO, Silvia, 2000, "El cuerpo de las creencias”, Suplemento Antropológico, 35 (2): 189-242.

CITRO, Silvia, 2009, Cuerpos Significantes: Travesías de Una Etnografía Dialéctica. Buenos Aires, Biblos/Culturalia.

CITRO, Silvia, 201 1, Cuerpos Plurales: Antropología de y desde los Cuerpos. Buenos Aires, Biblos/ Culturalia.

CORDEU, Edgardo, 1969-1970, "Aproximación al horizonte mítico de los tobas", Runa, 12 (1-2): 67-176.

CORDEU, Edgardo, et al., s.d., Memorias Etnohistóricas del Gran Chaco, informe científico final del Proyecto PICT-BID 98 4400, Buenos Aires.

CORDEU, Edgardo, y Alejandra SIFFREDI, 1971, De la Algarroba al Algodón: Movimientos Milenaristas del Chaco Argentino. Buenos Aires, Juárez Editor.

CÓRDOBA, Lorena, Federico BOSSERT, y Nicolás RICHARD (comps.), 2015, Capitalismo en las Selvas: Enclaves Industriales en el Chaco y Amazonía Indígenas (1850-1950). San Pedro de Atacama, Ediciones del Desierto.

DESCOLA, Philippe, 1986, La nature domestique: Symbolisme et praxis dans l'écologie des Achuar. París, Maison des Sciences de l'Homme.

DESCOLA, Philippe, 1996, "Constructing nature: symbolic ecology and social practice", en P. Descola y G. Pálsson (comps.), Nature and Society. Londres y Nueva York, Routledge. DESCOLA, Philippe, 2005, Par-delà nature et culture. París, Gallimard. 
DESCOLA, Philippe, 2014, La Composition des mondes: Entretiens avec Pierre Charbonnier. París, Flammarion.

DESCOLA, Philippe, y Anne-Christine TAYLOR, 1993, "Introduction", L'Homme, XXXIII (2-4): 13-24.

DI GIMINIANI, Piergiorgio, 2013, “The contested rewe: sacred sites, misunderstandings, and ontological pluralism in Mapuche land negotiations", Journal of the Royal Anthropological Institute, 19: 527-544.

FAUSTO, Carlos, y Michael HECKENBERGER (comps.), 2007, Time and Memory in Indigenous Amazonia: Anthropological Perspectives. Gainesville, University Press of Florida.

FERNÁNDEZ, Analía, y José BRAUNSTEIN, 2001, "Historias de Pampa del Indio", en IV Congreso Argentino de Americanistas, tomo 2. Buenos Aires, Dunken, 161-193.

GORDILLO, Gastón, 2004, Landscapes of Devils: Tensions of Place and Memory in the Argentinean Chaco. Durham, Duke University Press.

GORDILlO, Gastón, 2005, Nosotros Vamos a Estar Acá para Siempre. Buenos Aires, Biblos.

GORDILlO, Gastón, 2006, En el Gran Chaco: Antropologías e Historias. Buenos Aires, Prometeo.

GORDILlO, Gastón, 2010, Lugares de Diablos: Tensiones del Espacio y la Memoria. Buenos Aires, Prometeo.

GORDILlO, Gastón, y Juan LEGUIZAMÓN, 2002, El Río y la Frontera: Movilizaciones Aborígenes, Obras Públicas y Mercosur en el Pilcomayo. Buenos Aires, Biblos.

GOW, Peter, 2001, An Amazonian Myth and Its History. Oxford, Oxford University Press.

HANKS, William F., e Carlo SEVERI (comps.), 2014, dossier "Translating worlds: the epistemological space of translation", HAU: Journal of Ethnographic Theory, 4 (2).

HERZFELD, Mickael, 2001, "Orientations: anthropology as a practice of theory", em M. Herzfeld (org.), Anthropology: Theoretical Practice in Culture and Society. Londres, Blackwell/ /UNESCO, 1-20.

HILL, Jonathan (comp.), 1988, Rethinking History and Myth: Indigenous South American Perspectives on the Past. Urbana, University of Illinois Press.

HOLBRAAD, Martin, y Morten PEDERSEN, 2017, The Ontological Turn. Cambridge, Cambridge University Press.

HOLBRAAD, Martin, Morten PEDERSEN, y Eduardo Viveiros de CASTRO, 2014, "The politics of ontology: anthropological positions", Society for Cultural Anthropology, Editor's Forum: Theorizing the Contemporary, Fieldsites, < http://culanth.org/fieldsights/462-the -politics-of-ontology-anthropological-positions > (última consulta en junio de 2019).

IDOYAGA MOLINA, Anatilde, 1992, "Significación y simbolismo acuático entre los pilagá", Scripta Ethnologica, 14: 7-13.

IDOYAGA MOLINA, Anatilde, 1994, "Representación de los seres míticos pilagá", Scripta Ethnologica, 16: 7-21.

IDOYAGA MOLINA, Anatilde, 2000, Chamanismo, Brujería y Poder en América Latina. Buenos Aires, CAEA-Conicet.

IÑIGO CARRERA, Nicolás, 1979, La Violencia como Potencia Económica: Chaco 1879-1940. Buenos Aires, Centro Editor de América Latina.

IÑIgO CARRERA, Nicolás, 1983, La Colonización del Chaco. Buenos Aires, Centro Editor de América Latina.

IÑIgO CARrerA, Valeria, 2008, Sujetos Productivos, Sujetos Políticos, Sujetos Indígenas: Las Formas de Su Objetivación Mercantil entre los Tobas del Este de Formosa. Buenos Aires, Facultad de Filosofía y Letras, Universidad de Buenos Aires, tesis doctoral. 
KALISH, Hannes, y Ernesto UNRUH, 2004, "Enlhet-enenlhet: una familia lingüística chaqueña", Thule: Rivista di Studi Americanisti, 12-13: 207-231.

KARSTEN, Rafael, 1932, "Indian tribes of the Argentine and Bolivian Chaco", Societas Scientiarum Fennica, 4: 10-236.

KOHN, Eduardo, 2012, "Proposal 1: Anthropology beyond the human", Cambridge Anthropology, 30 (2): 136-146.

KOHN, Eduardo, 2013, How Forests Think: Toward an Anthropology Beyond the Human. Los Angeles, University of California Press.

LATOUR, Bruno, 1991, Nous n'avons jamais été modernes: Essais d'anthropologie symétrique. París, Editions La Découverte.

LATOUR, Bruno, 2012, Enquête sur les modes d'existence: Une anthropologie des Modernes. París, Editions La Découverte.

LOEWEN, Jakob, Albert BUCKWALTER, y James KRATZ, 1997 [1965], "Shamanism, illness and power in Toba church life”, Practical Anthropology, 12: 250-280.

LÓPEZ, Alejandro, 2007, Astronomía, Identidad y Cambio en Comunidades Mocovies del Chaco Argentino. Córdoba, Facultad de Filosofía y Humanidades, Universidad Nacional de Córdoba, tesis de maestría.

LÓPEZ, Alejandro, 2013, "Las texturas del cielo: una aproximación a las topologías moqoit del poder”, en F. Tola, C. Medrano y L. Cardin (comps.), Gran Chaco: Ontologías, Poder, Afectividad. Buenos Aires, Rumbo Sur / Ethnographica/IWGIA, 103-131.

LÓPEZ, Alejandro, y Sixto GIMÉNEZ BENÍTEZ, 2008, "The Milky Way and its structuring functions in the worldview of the Mocoví of Gran Chaco", Archaeologia Baltica, 10 : 21-24.

LÓPEZ, Alejandro, y Sixto GIMÉNEZ BENÍTEZ, 2009a, "Bienes europeos y poder entre los mocovíes del Chaco argentino", Archivos: Departamento de Antropología Cultural, 4-2006: $191-216$.

LÓPEZ, Alejandro, y Sixto GIMÉNEZ BENÍTEZ, 2009b, “Monte, campo y pueblo: el espacio y la definición de lo aborigen entre las comunidades mocovíes del Chaco argentino", en N. Ellison y M. Martínez Mauri (comps.), Paisaje, Espacio y Territorio: Reelaboraciones Simbólicas y Reconstrucciones Identitarias en América Latina. Quito, Abya Yala, 163-179.

MARTÍNEZ CROVETTO, Raúl, 1975, "Folklore toba oriental II: relatos fantásticos de origen chamánico", Suplemento Antropológico, 10 (1-2): 177-205.

MEDrano, Celeste, 2012, Zoo-Sociología Qom: De cómo los Tobas y los Animales Trazan sus Relaciones en el Gran Chaco. Buenos Aires, Facultad de Filosofía y Letras, Universidad de Buenos Aires, tesis doctoral.

MEDRANO, Celeste, 2013, “Devenir-en-transformación: debates etnozoológicos en torno a la metamorfosis animal entre los qom", en F. Tola, C. Medrano y L. Cardin (comps.), Gran Chaco: Ontología, Poder, Afectividad. Buenos Aires, IWGIA/Rumbo Sur/Ethnographica, 77-101.

MEDRANO, Celeste, Florencia TOLA, y Valentín SUAREZ, 2016, "La historia de los qom: una historia no sólo humana. Regímenes de historicidad y territorio en el Chaco argentino", presentado en el Segundo Congreso Internacional Los Pueblos Indígenas de América Latina, siglos XIX-XXI: Avances, Perspectivas y Retos, Santa Rosa (La Pampa), septiembre.

MESSINEO, Cristina, 2003, Lengua Toba (Guaycurú): Aspectos Gramaticales y Discursivos. Munich, Lincom Europa. 
MESSINEO, Cristina, 2014, Arte Verbal Qom: Consejos, Rogativas, Relatos. Buenos Aires, Rumbo Sur / Ethnographica.

MÉTRAUX, Alfred, 1946, Myth of the Toba and Pilagá Indians of the Gran Chaco. Filadelfia, American Folklore Society.

MÉTRAUX, Alfred, 1967, Religions et magies indiennes d'Amérique du Sud. París, Gallimard.

MILLER, Elmer, 1973, "The linguistic and ecological basis for Argentine Toba social categories", presentado en el Congress of ICAES, Chicago.

MILler, Elmer, 1979, Los Tobas Argentinos: Armonía y Disonancia en Una Sociedad. México, DF, Siglo XXI.

MORELLO, Jorge, Andrea RODRÍGUEZ, y Mariana SILVA, 2009, "Clasificación de ambientes en áreas protegidas de las ecorregiones del Chaco húmedo y seco”, en J. Morello y A. Rodríguez (comps.), El Chaco Sin Bosques: La Pampa o el Desierto del Futuro. Buenos Aires, Orientación Gráfica, 53-91.

OSUNA, Lilia Juanita, 1977, “El Chaco y su población, 1895-1970”, Folia Histórica del Nordeste, 2: 26.

PALAVECINO, Enrique, 1935, "Breve noticia sobre la religión de los indios del Chaco", Relaciones de la Sociedad Argentina de Antropología, 4: 85-91.

PALAVECINO, Enrique, 1964, "Nota sobre la mitología chaqueña", Homenaje a Fernando Márquez Miranda. Madrid, s.ed., 284-292.

PALAVECINO, Enrique, 1969-1970, “Mitos de los indios tobas", Runa, 12 (1-2): 177-199.

PALMER, John, 1995, "Wichi toponymy”, Hacia Una Nueva Carta Étnica del Gran Chaco, 6: 3-64.

PALMER, John, 1997, Wichi Goodwill: Ethnographic Allusions. Oxford, University of Oxford, tesis doctoral.

RENSHAW, John, 2002, The Indians of the Paraguayan Chaco: Identity and Economy. Lincoln, NE, University of Nebraska Press.

REYBURN, Willian D., 1954, The Toba Indians of the Argentine Chaco: An Interpretative Report. Indiana, Mennonite Board of Missions y Charities.

RICHARD, Nicolás (comp.), 2008, Mala Guerra: Los Indígenas en la Guerra del Chaco (1932-35). Asunción y París, ServiLibro / Museo del Barro / CoLibris.

RICHARD, Nicolás, 201 1, "La querelle des noms: chaînes et strates ethnonymiques dans le Chaco boreal", Journal de la société des américanistes, 97 (2): 201-230.

SALAMANCA, Carlos, 2006, En se glissant dans les fisures de l'utopie. París, EHESS, tesis doctoral.

SAlAmanCA, Carlos, 201 1, Movilizaciones Indígenas, Mapas e Historias por la Propiedad de la Tierra en el Chaco Argentino: La Lucha de las Familias Tobas por Poxoyâxaic Alhua. Buenos Aires, IWGIA y FLACSO.

SALAMANCA, Carlos, y Florencia TOLA, 2002, "La brujería como discurso político en el Chaco argentino", Desacatos, 9: 96-116.

SENDÓn, Pablo, y Diego VILlar (comps.), 2013, Al Pie de los Andes: Estudios de Etnología, Arqueología e Historia. Cochabamba, Itinerarios/ILAMIS.

STENGERS, Isabelle, 2005, “The cosmopolitical proposal”, en B. Latour y P. Weibel (comps.), Making Things Public: Atmospheres of Democracy. Cambridge, The MIT Press.

STRATHERn, M., 1988, The Gender of the Gift. Berkeley, University of California Press.

SURRAllÉS, Alexandre, 2003, Au cour du sens: Perception, affectivité, action chez les Candoshi. París, CNRS y Editions de la Maison des Sciences de l'Homme. 
TOLA, Florencia, 2012, Yo No Estoy Solo en Mi Cuerpo: Cuerpos-Personas Múltiples entre los Tobas del Chaco Argentino. Buenos Aires, Biblos/Culturalia.

TOLA, Florencia, Celeste MEDRANO, y Lorena CARDIN (comps.), 2013, Gran Chaco: Ontologías, Poder, Afectividad. Buenos Aires, Rumbo Sur/Ethnographica.

TOLA, Florencia, y Valentín SUAREZ, 2016, El Teatro Chaqueño de las Crueldades: Memorias Qom de la Violencia y el Poder. Buenos Aires, IIGHI/EREA/Ethnographica.

TOMASINI, Juan Alfredo, 1969-1970, "Señores de los animales, constelaciones y espíritus en el bosque, en el cosmos mataco-mataguayo", Runa, 12 (1-2): 427-443.

TOMASINI, Juan Alfredo, 1978-1979, "La narrativa animalística entre los toba de occidente", Scripta Ethnologica, 5 (1): 52-81.

TRINCHERO, Héctor, Daniel PICCININI, y Gastón GORDILlO (comps.), 1992, Capitalismo y Grupos Indigenas en el Chaco Centro-Occidental (Salta y Formosa)/I. Buenos Aires, Centro Editor de América Latina.

VILLAR, Diego, y Isabelle COMBÈS (comps.), 2012, Las Tierras Bajas de Bolivia: Miradas Históricas y Antropológicas. Santa Cruz de la Sierra, Colección Ciencias Sociales de El País.

VUOTO, Patricia, y Pablo WRIGHT, 1991, "Crónicas del Dios Luciano: un culto sincrético de los toba pilagá del Chaco argentino”, Religiones Latinoamericanas, 2: 149-180.

WAGNER, Roy, 1975, The Invention of Culture. Englewood Cliffs, NJ, Prentice-Hall.

WILBERT, Johannes, y Karin SIMONEAU (comps.), 1982, Folk Literature of the Toba Indians, vol. I. Los Angeles, University of California.

WRIGHT, Pablo, 1990, "Crisis, enfermedad y poder en la iglesia cuadrangular toba", Cristianismo y Sociedad, 105: 15-37.

WRIGHT, Pablo, 1992, “Toba Pentecostalism revisited”, Social Compass, 39 (3): 355-375.

WRIGHT, Pablo, 2002, "L'evangelio: pentecôtisme indigène dans le Chaco argentin”, Social Compass, 49 (1): 43-66.

WRIGHT, Pablo, 2008, Ser-en-el-Sueño: Crónicas de Historia y Vida Toba. Buenos Aires, Editorial Biblos/Culturalia.

WRIGHT, P., y J. BRAUNSTEIN, 1990, “Tribus toba: entre la historia, la demografía y la lingüística”, Hacia Una Nueva Carta Étnica del Gran Chaco, 1: 1-11. 